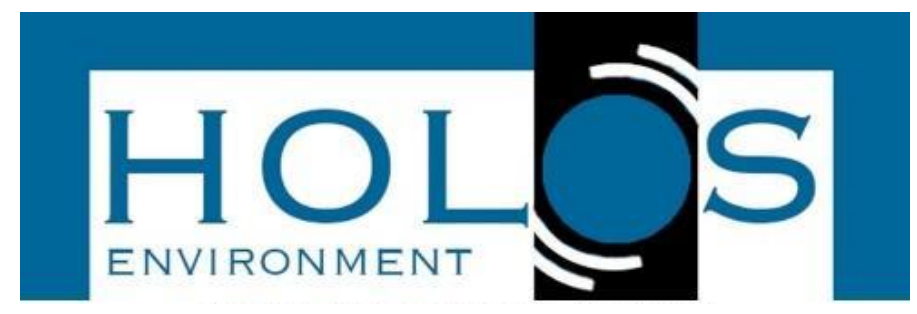

\title{
MASSA ESPECÍFICA E TEOR DE UMIDADE AO LONGO DO FUSTE PARA CORDIA TRICHOTOMA E CORDIA AMERICANA E SUAS CORRELAÇÕES
}

\section{SPECIFIC MASS AND MOISTURE CONTENT ALONG THE STEM FOR CORDIA TRICHOTOMA AND CORDIA AMERICANA AND THEIR CORRELATIONS}

\author{
Laura da Silva Zanchetta ${ }^{1}$; Eduarda Bandera ${ }^{1}$; Tauana de Souza Mangini ${ }^{1}$; Luana Candaten²; \\ Adriana Maria Iora ${ }^{1}$; Jonathan William Trautenmüller ${ }^{3}$; Rômulo Trevisan ${ }^{1}$ Elder Eloy ${ }^{1}$
}

Artigo recebido em: 02/06/2020 e aceito para publicação em: 12/08/2020.

DOI: http:/dx.doi.org/10.14295/holos.v20i4.12399

\begin{abstract}
Resumo: A variação da massa específica da madeira pode ocorrer entre e dentre espécies e até mesmo dentro da mesma árvore. A compreensão do comportamento dessa propriedade, através da relação entre espécies do mesmo gênero, é relevante para avaliar os usos dessas madeiras para os fins pretendidos. Por esta razão, o objetivo desse estudo foi determinar a massa específica e teor de umidade ao longo do fuste para Cordia trichotoma e Cordia americana e suas correlações quanto as propriedades físicas. As árvores selecionadas de ambos indivíduos foram seccionadas em discos nas posições relativas de $25,50,75$ e $100 \%$, considerando a altura comercial determinada a partir do primeiro galho vivo, bem como a $0,10 \mathrm{~m}$ (altura do toco) e no DAP (1,30 m do solo), de onde retirou-se cunhas para a determinação da variação longitudinal e correlações do teor de umidade, massa específica básica, aparente seco ao ar (14 a 15\% na região do estudo) e saturada. Os resultados indicaram um decréscimo dos valores de todas as massas específicas nas posições base-topo para as duas espécies florestais analisadas, variação inversa ao apresentado pelo teor de umidade do material. Com base nos dados analisados, os parâmetros físicos da madeira de ambas as espécies apresentaram correlações positivas entre si. Os valores médios aritméticos de massa específica básica para as madeiras de C. trichotoma e C. americana, 0,379 e $0,484 \mathrm{~g} / \mathrm{cm}^{3}$, respectivamente, caracterizam os materiais para uso na fabricação de móveis, lâminas faqueadas e peças valiosas tornadas.
\end{abstract}

Palavras-chave: Boraginaceae. Espécies nativas. Característica tecnológica. Perfil longitudinal.

\begin{abstract}
The variation in the specific mass of the wood may occur between and among species and even within the same tree, understanding the behavior of this property, through the relationship between species of the same genus is interesting in order to estimate the uses of these woods. Therefore, the objective of this study was to determine the specific mass and moisture content along the stem for Cordia trichotoma and Cordia americana and their correlations regarding physical properties. The trees selected from both individuals were sectioned in discs in the relative positions of $25,50,75$ and $100 \%$, considering the commercial height determined from the first live branch, as well as at $0.10 \mathrm{~m}$ (stump height) and at the DAP (1.30 m from the soil), from where wedges were removed to determine the longitudinal variation and correlations of moisture content, basic specific mass, apparent air-dried (14 to 15\% in the study region) and saturated. The results indicated a decrease in the values of all specific masses in the base-to-pound positions for the two forest species analyzed, inverse variation to that presented by the moisture content of the material. Based on the analyzed data, the physical parameters of the wood of both species presented positive correlations between

\footnotetext{
1 Universidade Federal de Santa Maria (UFSM), Santa Maria, RS E-mails: (zanchettalaura2@gmail.com, duda bandera@outlook.com, tauanamangini@yahoo.com, adriiora26@gmail.comromulo trevisan@ufsm.br, elderufsm@gmail.com)

2 Universidade de São Paulo (USP), São Paulo, SP. E-mail: (luana candaten@outlook.com)

${ }^{3}$ Universidade Federal do Paraná (UFPR), Curitiba, PR. E-mail: (jwtraute@hotmail.com)
} 
them. The arithmetic mean values of basic specific mass for the woods of $C$. trichotoma and $C$. americana, 0.379 and $0.484 \mathrm{~g} / \mathrm{cm}^{3}$, respectively, characterize the materials for use in the manufacture of furniture, sliced veneers and valuable parts turned.

Keywords: Boraginaceae. Native species. Technological characteristic. Longitudinal section.

\section{INTRODUÇÃO}

A vasta diversidade de biomas responsáveis pela composição do Brasil ocasiona grande heterogeneidade biológica e madeireira no país quando comparado a outros ecossistemas (TRAUTENMÜLLER et al., 2017). Dessa maneira, o sortimento de espécies, principalmente arbóreas, pode ser ocasionado a partir do clima temperado, o qual é responsável por condições edafoclimáticas que favorecem elevadas produções florestais e madeiras de alto valor agregado (SOUZA et al., 2013).

Nos dias atuais, a utilização de recursos naturais originários do próprio país como, por exemplo, a madeira, vem ganhando espaço no mercado, o que pode ser explicado pela ampla utilização em setores comerciais (SOUZA et al., 2013). O ramo madeireiro engloba a aplicação de inúmeras espécies, sendo que as pertencentes ao gênero Cordia são amplamente empregadas pelo alto potencial produtivo (MOULIN et al., 2016). O mesmo é composto por, aproximadamente, 250 espécies nativas, possuindo extensa ocorrência desde a região central da Argentina até a América Central (MATIAS et al., 2015).

Uma das espécies provenientes do gênero citado é a Cordia trichotoma (Vell.) Arráb. ex Steud., a qual pertence à família Boraginaceae e é conhecida popularmente como Louropardo. No Brasil, a mesma ocorre espontaneamente nas florestas Pluviais Atlânticas semidecíduas e no cerrado, desde o Rio Grande do Sul até o Ceará (WILLE et al., 2017). Além disso, a madeira é caracterizada por compreender pouca distinção entre cerne e alburno, massa específica moderada e simples trabalhabilidade, sendo indicada para usos como, fabricação de móveis, lâminas faqueadas e peças valiosas tornadas (ZIMMERMANN et al., 2017).

Outra espécie desse mesmo gênero que é amplamente empregada é a $C$. americana (Linnaeus) Gottshling \& J.S. Mill, também pertencente à família Boraginaceae e tem como nome popular Guajuvira, apresentando incidência ao longo da Argentina, Paraguai e Brasil, sendo de importância na região das florestas do Alto Uruguai (TRAUTENMÜLLER et al., 2017). Pelo alto valor agregado à essa madeira faz-se indicações nos mais variados 
segmentos como, por exemplo, na construção civil, obras externas, cabos de ferramentas, paisagismo e ainda, no reflorestamento, as quais podem ser explicadas pela qualidade do produto (CARVALHO, 2003).

Um dos parâmetros essenciais para utilização e determinação dos atributos do material é a massa específica (OSBORNE, 2016), a qual representa a porção de matéria lenhosa por unidade de volume ou o volume de espaços vazios existentes em uma peça (ZAQUE et al., 2018). A alteração desse indicador, relaciona-se diretamente à espessura da parede celular, podendo ocorrer, dentro da árvore, da medula para a casca, da base para topo e ainda, associada à variações genéticas e ambientais (ZAQUE et al., 2018).

É possível observar no cenário atual que são minoria os estudos baseados na utilização de espécies nativas, demonstrando a carência de pesquisas relacionadas à caracterização tecnológica da madeira das mesmas. Desse modo, o presente trabalho tem por objetivo a massa específica e teor de umidade ao longo do fuste para Cordia trichotoma e Cordia americana e suas correlações.

\section{MATERIAL E MÉTODOS}

Para a condução do experimento foram abatidos quatro indivíduos de $C$. trichotoma provenientes do município de Palmitinho, localizado a uma latitude de $27^{\circ} 21^{\prime}$ '04" Sul e longitude de $53^{\circ} 33^{\prime} 27^{\prime \prime}$ Oeste; e três árvores de $C$. americana, oriundas da cidade de Três Passos, situada a uma latitude de $27^{\circ} 23^{\prime} 36^{\prime \prime}$ Sul e longitude de $54^{\circ} 05^{\prime} 06^{\prime \prime}$ Oeste, ambos no estado do Rio Grande do Sul, conforme Figura 1.

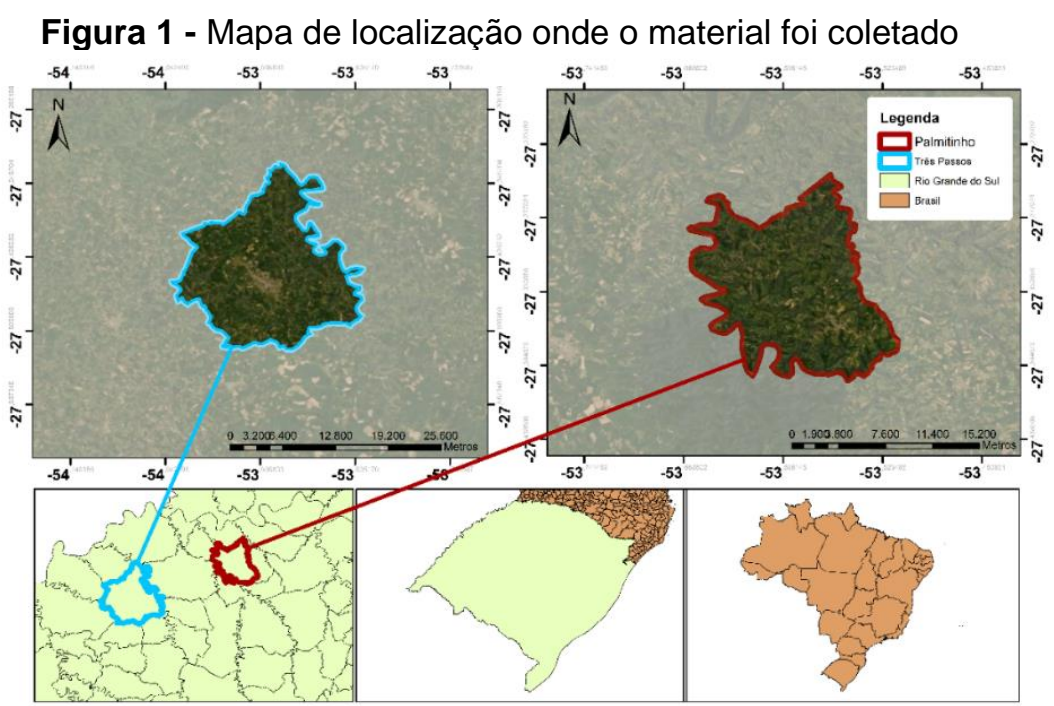

Fonte: Elaborado pelos autores 
Desse material, retiraram-se discos nas porções de $0,25,50,75,100 \%$ e DAP $(1,30$ $\mathrm{m}$ do solo), considerando-se altura total das árvores determinada a partir da altura do primeiro galho vivo. Os mesmos foram demarcados e acondicionados em sacos plásticos para o transporte até o laboratório. Os discos foram seccionados em cunhas simetricamente opostas, contendo a medula, as quais foram identificadas e expostas a secagem ao ar até que atingissem o teor de umidade de equilíbrio com o ambiente, sendo que na região de Frederico Westphalen, é de aproximadamente $14 \%$ a $15 \%$.

Dessas cunhas, foram obtidos a massa e o volume para a determinação das massas específicas básica, seco ao ar (14 a 15\%) e saturada, os volumes foram obtidos a partir da técnica da balança hidrostática e a mensuração da massa pelo método gravimétrico em balança analítica com precisão de 0,01 $\mathrm{g}$.

Para a obtenção do volume saturado e massa saturada, as amostras foram submersas em água para a completa saturação das fibras, já, para obtenção do peso à $0 \%$ de umidade, as cunhas foram submetidas a secagem em estufa de circulação de ar forçada a $103 \stackrel{\circ}{\circ}$ até que atingissem massa constante.

A determinação das massas específicas básica, aparente seco ao ar e aparente saturada no sentido base-topo das árvores seguiram as recomendações da norma ASTM D-143-94 (1995). Os dados foram analisados estatisticamente com o auxílio do programa $\mathrm{R}$, onde realizou-se o teste de correlação de Pearson afim de verificar a correlação das propriedades físicas entre e dentre as espécies estudadas.

\section{RESULTADOS E DISCUSSÃO}

Os valores de massa específica básica, aparente a 12\% e aparente saturada, assim como o teor de umidade das espécies florestais $C$. trichotoma e $C$. americana, mostraram, de maneira geral, uma tendência de redução das médias para essas propriedades no sentido base-topo do tronco (Tabela 1). A escassez de literatura disponível estudando a madeira de espécies nativas, conforme as do presente estudo, tornou necessário a discussão e comparação dos resultados com demais espécies folhosas. 
Tabela 1 - Características físicas de massa específica e teor de umidade ao longo do fuste das madeiras de Louro-pardo e Guajuvira

\begin{tabular}{|c|c|c|c|c|c|c|c|c|}
\hline \multirow[t]{2}{*}{ Posição } & \multicolumn{4}{|c|}{$\begin{array}{c}\text { Louro-pardo } \\
\text { Cordia trichotoma }\end{array}$} & \multicolumn{4}{|c|}{$\begin{array}{c}\text { Guajuvira } \\
\text { Cordia americana }\end{array}$} \\
\hline & Meb & Me ap ar & Me ap sat & TU & Meb & Me ap ar & Me ap sat & TU \\
\hline $0,10 \mathrm{~m}$ & 0,420 & 0,583 & 1,109 & 165,3 & 0,538 & 0,737 & 1,209 & 122,5 \\
\hline DAP & 0,402 & 0,540 & 1,073 & 163,4 & 0,480 & 0,699 & 1,156 & 143,0 \\
\hline 25 & 0,380 & 0,466 & 1,081 & 185,4 & 0,494 & 0,694 & 1,150 & 133,3 \\
\hline 50 & 0,364 & 0,488 & 1,072 & 196,3 & 0,484 & 0,673 & 1,146 & 136,9 \\
\hline 75 & 0,358 & 0,487 & 1,071 & 199,9 & 0,439 & 0,665 & 1,104 & 152,8 \\
\hline 100 & 0,352 & 0,489 & 1,072 & 206,1 & 0,471 & 0,656 & 1,149 & 148,7 \\
\hline
\end{tabular}

Em que: Meb= massa específica básica em $\mathrm{g} / \mathrm{cm}^{3} ;$ Me ap ar\%= massa específica aparente seco ao ar em $\mathrm{g} / \mathrm{cm}^{3}$; Me ap sat= massa específica aparente saturada em $\mathrm{g} / \mathrm{cm}^{3} ; \mathrm{TU}=$ teor de umidade em \%; DAP= diâmetro à altura do peito $(1,30 \mathrm{~m}$ do solo); $0,10 \mathrm{~m}=$ Altura do toco, $25,50,75,100=$ Posições relativas com base na altura total das árvores em \%.

O comportamento observado no sentido base-topo da massa específica aparente saturada para espécie de $C$. trichotoma e massa específica básica para $C$. americana, não seguiram um padrão definido, com valores decrescendo até a porção do DAP e, nas demais alturas, apresentando uma oscilação.

Da mesma maneira, Eloy et al. (2013a) ao estudarem a madeira de E. grandis, constataram um decréscimo da massa específica básica na região da base até o DAP. Ainda, esse mesmo padrão também foi verificado na avaliação de indivíduos de Mimosa scabrella, sendo que os valores dessa mesma propriedade diminuíram até a região do DAP e a partir dessa posição, ocorreu um aumento sem tendência de estabilização com a altura (ELOY et al., 2013b).

Essa modificação dentro de uma mesma espécie pode ocorrer em razão das características anatômicas, como proporção entre cerne e alburno (GLASS; ZELINKA 2010). Conforme o estudo de Pereira et al. (2013), se a massa específica demonstrar uma tendência de acréscimo longitudinalmente, pode indicar a presença de madeira juvenil próxima ao topo e constituição de cerne na base da árvore.

A espécie de $C$. trichotoma apresentou variação dos resultados para todas as variáveis estudadas, sendo que, de maneira geral, as massas específicas decresceram e o teor de umidade evidenciou um acréscimo em relação ao sentido base-topo (Figura 2). Apenas a massa específica aparente a $12 \%$ decresceu uniformemente no sentido longitudinal, com valores variando de 0,583 a $0,489 \mathrm{~g} / \mathrm{cm}^{3}$. 
Em relação a massa específica básica, para o mesmo indivíduo em todas as alturas, os valores obtidos ficaram abaixo do encontrado por Moulin et al. (2016), que obtiveram uma média de $0,830 \mathrm{~g} / \mathrm{cm}^{3}$ estudando a madeira de Cordia glabrata, pertencente ao mesmo gênero e família das espécies do presente trabalho.

Figura 2- Variação longitudinal da massa específica aparente seco ao ar (14 a 15\%) (A), massa específica básica $(B)$ e massa específica aparente saturada (C) da madeira de Cordia trichotoma

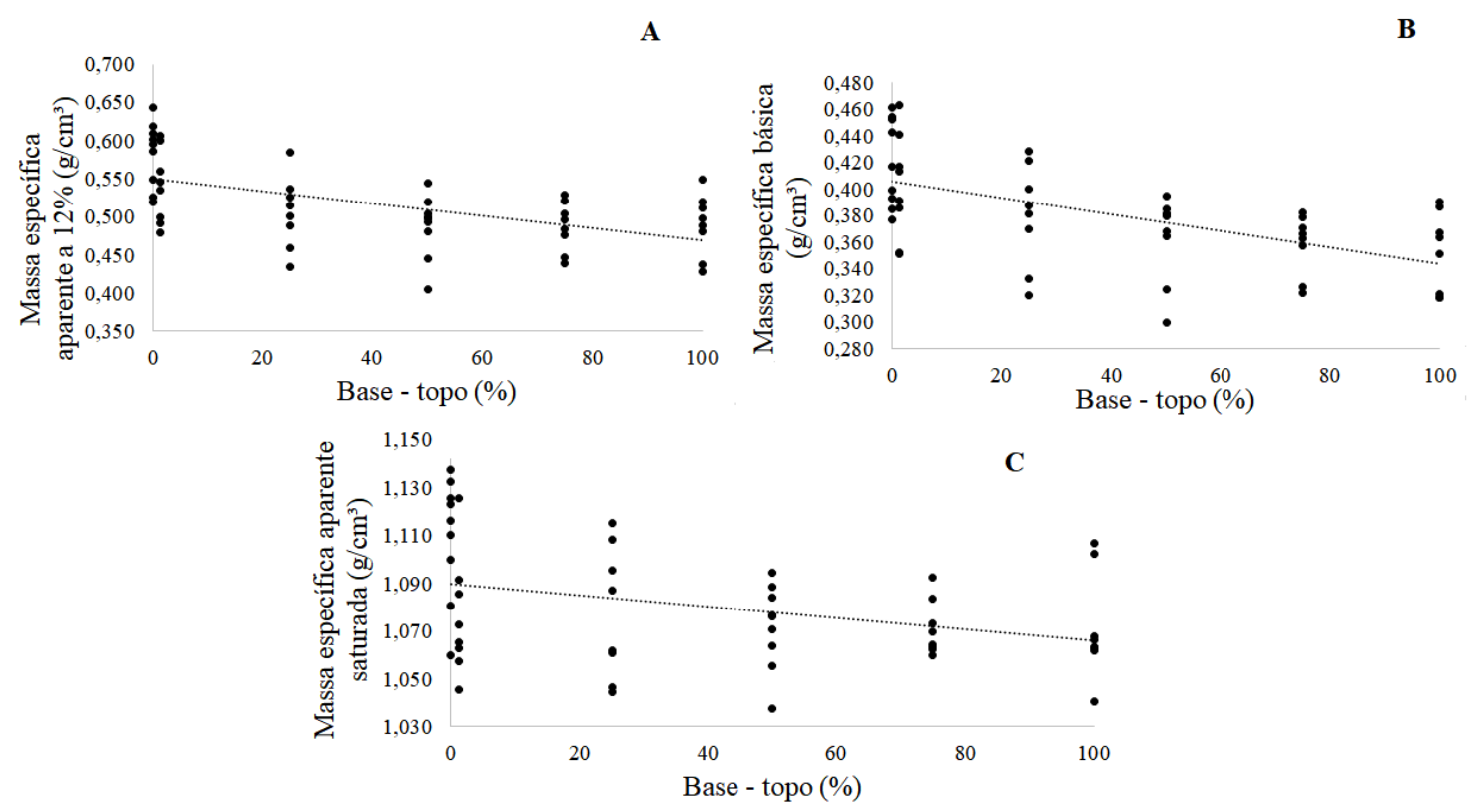

Fonte: Elaborado pelos autores.

A massa específica aparente a $12 \%$ analisada para a espécie de $C$. americana em todas as posições ao longo do fuste foram próximas das ciadas na literatura, para Souza et al. (2013) o valor relatado foi de $0,646 \mathrm{~g} / \mathrm{cm}^{3}$ no estudo de indivíduos de Patagonula americana L. (Guajuvira), com 25 anos de idade. Ainda, tratando-se da massa específica básica avaliada na presente pesquisa, esta variou de 0,538 a $0,471 \mathrm{~g} / \mathrm{cm}^{3}$, onde a menor média foi identificada na posição $75 \%$ da altura. 
Figura - Variação longitudinal da massa específica aparente seco ao ar (14 a 15) \% (A), massa específica básica $(B)$ e massa específica aparente saturada (C) da madeira de Cordia americana

A
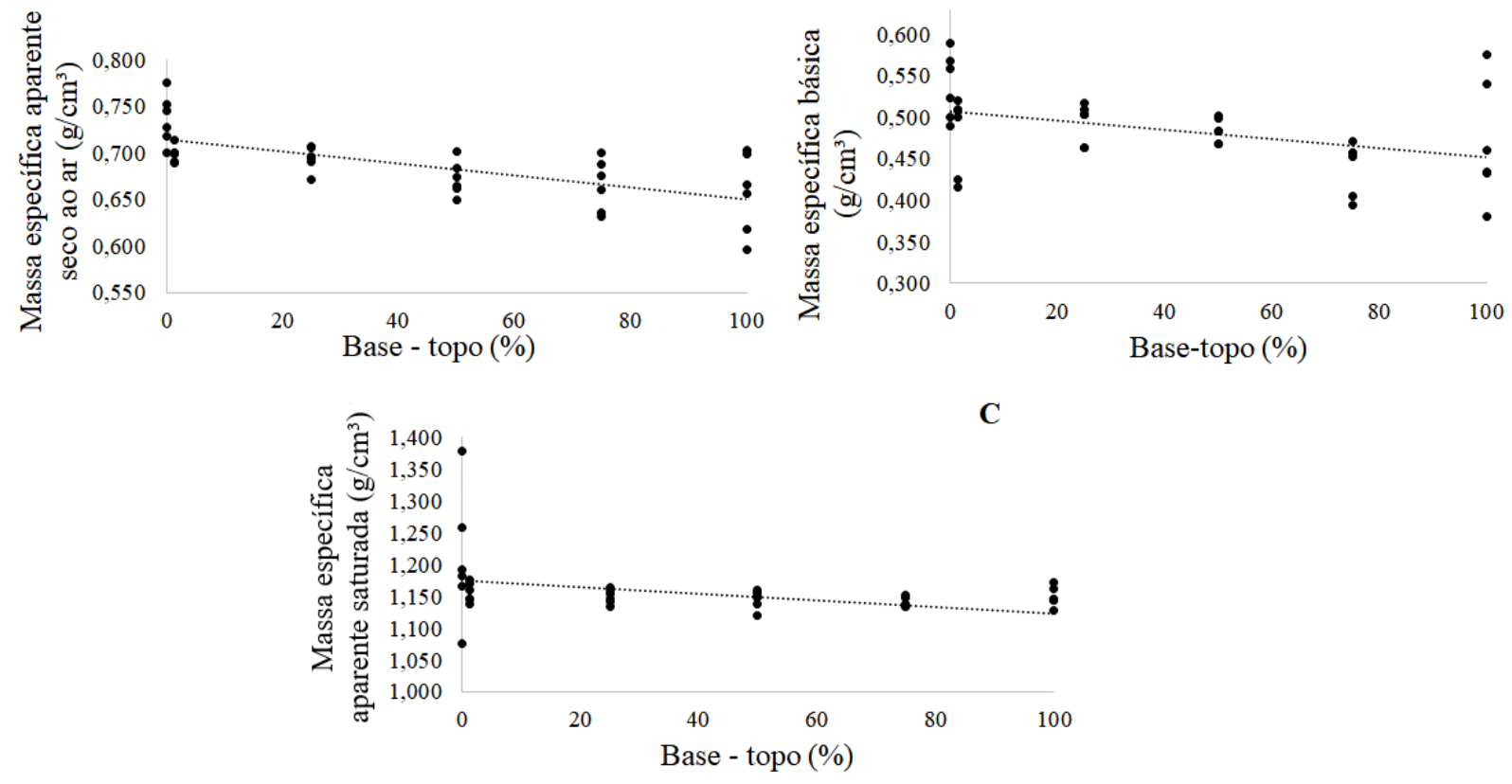

Fonte: Elaborado pelos autores.

O decréscimo de valores da posição base-topo para a massa específica básica da madeira de $C$. americana também foi constatado por Trautenmüller et al. (2014), porém para estes autores os resultados seguiram um padrão de decréscimo gradual ao longo do tronco, essa variação foi de $0,664 \mathrm{~g} / \mathrm{cm}^{3}$ a $0,558 \mathrm{~g} / \mathrm{cm}^{3}$.

Os resultados da massa específica aparente saturada, para ambos indivíduos estudados, também diminuíram com o aumento ao longo do fuste. Comportamento semelhante foi observado por Candaten et al. (2018 e 2019) para a madeira de M. tinctoria, e Myrcianthes pungens apresentando um valor de $1,330 \mathrm{~g} / \mathrm{cm}^{3}$ para a base e 1,215 g/cm 3 para o topo.

Conforme apresentado na Figura 4, a relação da disposição longitudinal teve uma correlação fortemente positiva com o teor de umidade. Esse resultado também ocorreu para as massas específicas entre as espécies, indicando que apesar da literatura abordar que a variação da massa específica comumente ocorre, entre e dentre espécies e até mesmo dentro da mesma árvore, as madeiras em questão, pertencentes à família Boraginaceae, não se comportaram de tal forma, apresentando semelhanças quanto a essas propriedades. 
Além disso, os valores das massas específicas, estão totalmente correlacionados aos teores de umidade ao longo do fuste (Figura 4), corroborando com o que foi apresentado na Tabela 1. Essa relação é inversamente proporcional, uma vez que, quanto mais elevado é o teor de umidade, menor é a massa específica. Estudos realizados por Candaten et al. (2018), com a espécie de Maclura tinctoria, explicaram que este comportamento está atrelado a relação do volume e da massa do material, pois quando o teor de umidade encontra-se em torno de $30 \%$, faixa de umidade em que ocorre o ponto de saturação das fibras, a madeira passa a alterar apenas o peso e não mais as suas dimensões, ambos são fatores determinantes no resultado da massa específica.

Figura 4 - Correlações de Pearson entre as variáveis físicas e as espécies do gênero Cordia.

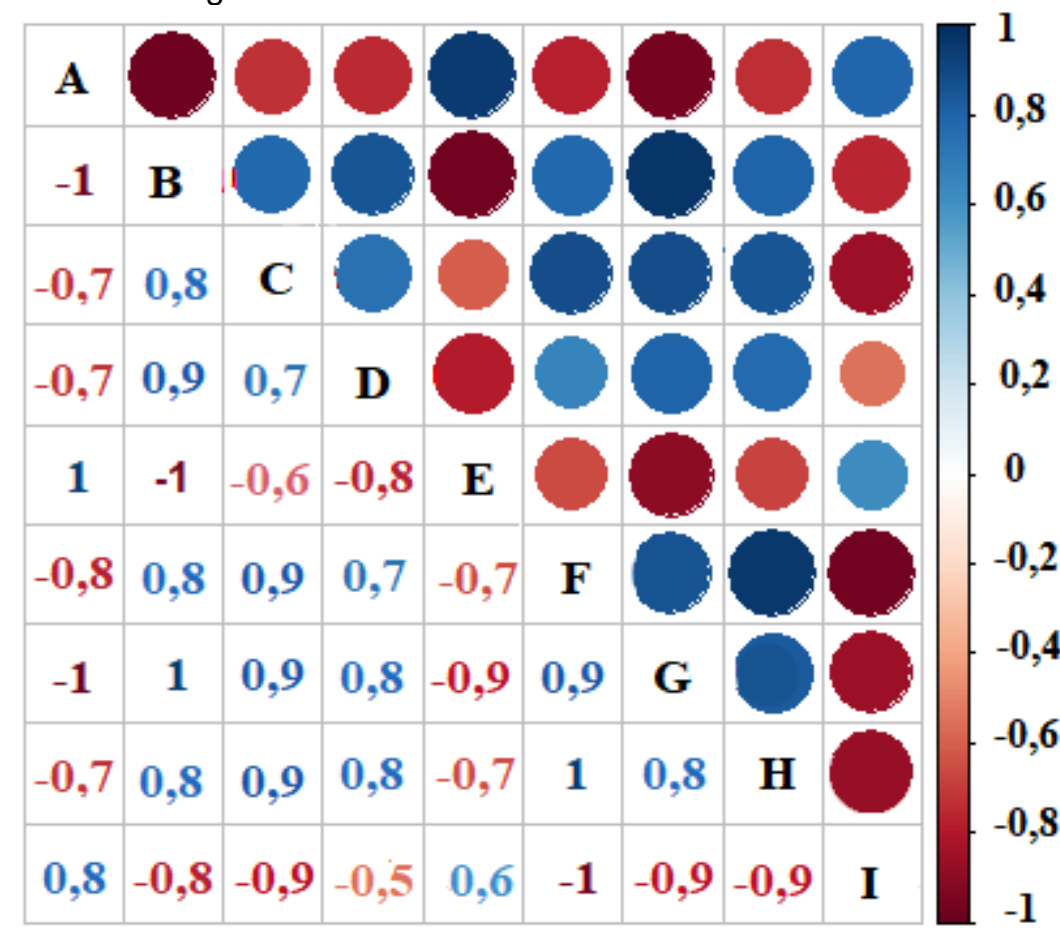

Fonte: Elaborado pelos autores.

Em que: $A=$ Posição ao longo do fuste; $B=$ Massa específica básica de Louro-pardo; $C=$ Massa específica aparente saturada de Louro-pardo; $D=$ Massa específica aparente a $12 \%$ de Louro-pardo; $\mathrm{E}=$ Teor de umidade de Louro-pardo; $\mathrm{F}=$ Massa específica básica de Guajuvira; $\mathrm{G}=$ Massa específica aparente saturada de Guajuvira; $\mathrm{H}=$ Massa específica aparente a $12 \%$ de Guajuvira; I= Teor de umidade de Guajuvira.

O teor de umidade apresentou um comportamento esperado de acordo com a correlação com as massas específicas das espécies, onde essas são negativas fazendo referência a proporcionalidade dessas propriedades, que com o aumento do teor de umidade, a massa específica da madeira é reduzida, conforme discutido anteriormente. $\mathrm{O}$ 
mesmo foi observado por Oliveira et al. (2005), onde avaliaram diferentes madeiras de Eucalyptus nas diferentes posições do tronco, observando a correlação positiva entre essas propriedades.

\section{CONCLUSÃO}

Existe variações entre as propriedades físicas estudadas para as espécies florestais (C. trichotoma e C. americana) nas diferentes alturas ao longo do fuste. As massas específicas apresentam uma tendência decrescente no sentido base-topo, enquanto o teor de umidade tende a aumentar. Além disso, há uma correlação positiva entre as espécies estudadas, indicando pouca variação entre as propriedades físicas da madeira pertencente à família Boraginaceae.

\section{REFERÊNCIAS}

CANDATEN, L.; MANGINI, T.; BANDERA, E.; TREVISAN, R.; COSTA, H.W.D. Relação da massa específica e teor de umidade da madeira de Maclura tinctoria ao longo do fuste. Enciclopédia Biosfera, Goiânia, v.15, n.28, p. 845-854, 2018. https://doi.org/10.18677/EnciBio 2018B68. Disponível em: https://www.conhecer.org.br/enciclop/2018B/AGRAR/relacao\%20da\%20massa.pdf.

CANDATEN, L.; BANDERA, E.; MANGINI, T.S; ZANCHETTA, L.S.; TREVISAN, R. Massa específica básica, aparente saturada e teor de umidade da madeira de Myrcianthes pungens (O. Berg) D. Legrand. Enciclopédia Biosfera, Goiânia, v. 16, n. 9, p.1026-1035, 2019. https://doi.org/10.18677/EnciBio 2019A85. Disponível em: http://www.conhecer.org.br/enciclop/2019a/agrar/massa.pdf. Acesso em: 25 jan. 2020.

CARVALHO, P.E.R. Espécies arbóreas brasileiras. Brasília: EMBRAPA Informação Tecnológica. Colombo, PR: EMBRAPA Florestas, 2003. p.1039.

ELOY, E.; CARON, B.O.; TREVISAN, R.; BEHLING, A.; SOUZA, V.Q.; SCHMIDT, D. Variação axial e efeito do espaçamento na massa específica da madeira de Eucalyptus grandis e Acacia mearnsii. Ciência da Madeira, Pelotas, n. 2, p. 215-227, 2013a. https://doi.org/10.12953/21776830.v04n02a07. Disponível em:

https://periodicos.ufpel.edu.br/ojs2/index.php/cienciadamadeira/article/view/4065/3209.

ELOY, E.; CARON, B.O.; TREVISAN, R.; SCHMIDT, D.; ZANON, M.L.Z.; BEHLING, A.; MONTEIRO, G.C. Variação longitudinal e efeito do espaçamento na massa específica básica da madeira de Mimosa scabrella e Ateleia glazioveana. Floresta, Curitiba, v. 43, n. 2, p.327-334, 2013b. Disponível em: https://www.revistas.ufpr.br/floresta/article/view/29266/20720.

GLASS, S. V.; ZELINKA, S. L. Moisture Relations and Physical Properties of Wood, Chapter 4. Wood handbook - Wood as an engineering material. General Department of Agriculture, Forest 
Service, Forest Products Laboratory. Madison, WI, U.S., 2010. Disponível em:

https://www.fpl.fs.fed.us/documnts/fplgtr/fplgtr190/chapter 04.pdf.

MATIAS, E.F.F.; ALVES, E.F.; SILVA, M.K.N.; CARVALHO, V.R.A.; COUTINHO, H.D.M.; COSTA, J.G.M. The genus Cordia: botanists, ethno, chemical and pharmacological aspects. Revista

Brasileira de Farmacognosia, Curitiba, v. 25, p. 542-552, 2015.

https://doi.org/10.1016/j.bjp.2015.05.012. Disponível em:

http://www.scielo.br/scielo.php?script=sci arttext\&pid=S0102-695X2015000500542.

MOULIN, J.C.; RODRIGUES, B.P.; OLIVEIRA, J.T.S.; ROSA, R.A.; OLIVEIRA, J.G.L.

Propriedades tecnológicas do lenho de louro-preto. Pesquisa Florestal Brasileira, Colombo, v. 36, n. 88, p. 415-421, 2016. https://doi.org/10.4336/2016.pfb.36.88.994. Disponível em:

https://pfb.cnpf.embrapa.br/pfb/index.php/pfb/article/view/994/534.

OLIVEIRA, J.T.S.; HELLMEISTER, J.C.; TOMAZELLO FILHO, M. Variação do teor de umidade e da densidade básica na madeira de sete espécies de eucalipto. Árvore, Viçosa, v. 29, n.1, p.115127, 2005. https://doi.org/10.1590/S0100-67622005000100013. Disponível em:

http://www.scielo.br/pdf/rarv/v29n1/24241.pdf.

OSBORNE, N.L. Estimating the density of coast Douglas-fir wood samples at diferente moisture contents using medical X-ray computed tomography. Computers and Electronics in Agriculture, v.127, p. 50-55, 2016. https://doi.org/10.1016/..compag.2016.06.003

PEREIRA, B. L. C.; OliVEIRA, A. C.; CARVALHO, A. M. M. L.; CARNEIRO, A. C. O.; VITAL, B. R.; SANTOS, L. C. Correlações entre a relação Cerne/Alburno da madeira de eucalipto, rendimento e propriedades do carvão vegetal. Scientia Forestalis, Piracicaba, v. 41, n. 98, p. 217-225, 2013. Disponível em: https://www.ipef.br/publicacoes/scientia/nr98/cap07.pdf.

SOUZA, J.T.; FILIPINI, F.R.; BORTOLUZI, R.N.G.; BELTRAME, R.; VIVIAN, M.A.; MENEZES, W.M. Comportamento da flexão dinâmica na madeira de Patagonula americana L.E Ocotea catharinensis Mez. Ciência da Madeira, Pelotas, v. 4, n. 2, p. 228-237, 2013.

https://doi.org/10.12953/2177-6830.v04n02a08. Disponível em: https://periodicos.ufpel.edu.br/ojs2/index.php/cienciadamadeira/article/view/4058/3202.

TRAUTENMULÜLLER, J.W.; BORELLA, J.; MINATTI, M.; COSTA, S.JR.; WOYCIKIEVICZ, A.P.F.; BALBINOT, R.; SANQUETTA, C.R. Avaliação de plantas de Cordia americana em viveiro utilizando caracteres morfológicos. BIOFIX Scientific Journal, Curitiba, v.2, n. 2, p. 65-70, 2017. https://doi.org/10.5380/biofix.v2i2.55512. Disponível em: https://revistas.ufpr.br/biofix/article/view/55512/33990.

TRAUTENMÜLLER, J.W.; BALBINOT, R.; BORELLA, J.; TREVISAN, R. BALESTRIN, D.; VENDRUSCOLO, R.; SABADINI, A.M. Variação longitudinal da massa específica básica da madeira de Cordia americana e Alchornea triplinervia. Ciência Rural, Santa Maria, v. 44, n.5, p. 817-821, 2014. https://doi.org/10.1590/S0103-84782014000500009. Disponível em: http://www.scielo.br/scielo.php?script=sci arttext\&pid=S0103-84782014000500009.

ZAQUE, L.A.M.; FERREIRA, M.D.; MELO, R.R. Variação radial e longitudinal da massa específica básica da madeira de Araucaria angustifolia com diferentes idades. Pesquisa Florestal Brasileira, Colombo, v. 38, p.1-5, 2018. https://doi.org/10.4336/2018.pfb.38e201601368. Disponível em: https://pfb.cnpf.embrapa.br/pfb/index.php/pfb/article/view/1368/663. 
ZIMMERMANN, A.P.L.; TABALDI, L.A.; FLEIG, F.D.; MICHELON, I. JR; MARANGON, G.P. Métodos de transplantio para utilização de mudas de regeneração natural de Cordia trichotoma. Agrária - Revista Brasileira de Ciências Agrárias, Recife, v.12, n.1, p.74-78, 2017. https://doi.org/10.5902/1980509830332. Disponível em: http://www.agraria.pro.br/ojs2.4.6/index.php?journal=agraria\&page=article\&op=view\&path\%5B\%5D=agraria $v 12 i 1 a 5416 \&$ path $\% 5 \mathrm{~B} \% 5 \mathrm{D}=4958$.

WILLE, V.K.D.; WASTOWSKI, A.D.; PEDRAZZI, C.; SAUER, M.P. Composição química da madeira de Cordia trichotoma (Vell.) Arráb. ex Steud. Ciência Florestal, Santa Maria, v. 27, n. 4, p.1441-1449, 2017. Disponível em:

https://periodicos.ufsm.br/cienciaflorestal/article/view/30332/pdf > . 